\title{
A Study of Characteristics of Psychoemotional Status in First- Trimester Pregnant Women Living in a Northern Environment
}

\author{
Natalia I. Douglas, $\mathrm{PhD}, \mathrm{ScD}^{1^{*}}$; Evgeniya N. Nikolaeva, $\mathrm{PhD}^{1}$; Nyurguyana S. Baisheva ${ }^{1}$; \\ Olga N. Kolosova, $\mathrm{PhD}, \mathrm{ScD}^{2}$; Elena A. Belchusova ${ }^{3}$; Lubov’ E. Vasilieva \\ ${ }^{\prime} M$. K. Ammosov North-Eastern Federal University, Yakutsk, Russia \\ ${ }^{2}$ Institute for Biological Problems of Cryolithozone Siberian Branch of RAS, Yakutsk, Russia \\ ${ }^{3}$ Phthisiatry Research-Practice Center, Yakutsk, Russia
}

\begin{abstract}
This article presents the results of a study on psychoemotional stress observed in a northern environment, an important factor contributing to the development of abnormalities during pregnancy and leading to a risk of miscarriage in first-trimester (MT1) pregnant women.

Materials and Methods: A total of 147 MT1 pregnant women were included in the study, who were divided into 3 groups based on their health status: Group 1 (Control group) included basically healthy women $(n=24)$; Group 2 (Risk group) included women defined as vulnerable to risk factors $(\mathrm{n}=32$ ); Group 3 (Threatened group) included women hospitalized for threatened miscarriage $(\mathrm{n}=35)$. In Groups 2 and 3, patients were divided into 3 age groups: 18-24 years, 25-34 years, and $\geq 35$ years. Patients in the Control group were divided into 2 age groups, 18-24 years and 25-34 years, since women aged $\geq 35$ years were referred to Group 2. The psychoemotional status of the women was assessed using the Spielberger State-Trait Anxiety Inventory (STAI) in Yu.L.Khanin's adaptation, and the Eysenck Personality Questionnaire (EPQ).

Results: The results of our study showed the presence of age-specific features in the psychophysiological state of pregnant women living in the North, specifically, high anxiety levels. In all patient groups, psychoemotional stress tended to increase with age. The highest stress levels were observed among pregnant women from the Threatened miscarriage group, especially in 2 age subgroups (18-24 years and $\geq 35$ years). (International Journal of Biomedicine. 2019;9(3):233-236.)
\end{abstract}

Key Words: anxiety $\bullet$ aggression $\bullet$ rigidity $\bullet$ frustration

\section{Introduction}

Miscarriage is one of the most serious problems in international medicine. Exposure to various external factors, including biomedical, socioeconomic, and psychological ones, has a direct influence on the physiology and mental health of pregnant women, and can contribute to the development of the different types of pregnancy complications or pregnancy failure. ${ }^{(1-5)}$ As is commonly observed, a woman's body is most vulnerable to environmental exposure or unfavorable factors during early periods of pregnancy. All the major body organs and systems of the fetus are forming during early pregnancy,

*Corresponding author: Natalia I. Douglas, PhD, ScD. Head of the Department of Obstetrics and gynecology of the M. K. Ammosov North-Eastern Federal University. Yakutsk, the Republic of Sakha (Yakutia), the Russian Federation.E-mail: nduglas@yandex.ru which should later enable normal vital activity necessary for further development of the fetus and newborn baby. ${ }^{(6)}$ Despite advances in medical care, there is still a high rate of pregnancy complications during first-trimester (MT1), including spontaneous miscarriage. Emotional stress can be a possible reason, triggering desynchronization and maladaptation processes in the body, which could lead to pregnancy complications, and as a result, to miscarriage. ${ }^{(7)}$ In northern environments, observations have been made of psychoemotional stress resulting from exposure to certain extreme climate and geophysical factors. ${ }^{(8)}$ In view of the above, the aim of this work was to study the age-specific psychoemotional status of pregnant women living in a northern environment.

\section{Materials and Methods}

A total of 147 MT1 pregnant women were included in the study, who were divided into 3 groups based on their health 
status: Group 1 (Control group) included basically healthy women ( $\mathrm{n}=24)$; Group 2 (Risk group) included women defined as vulnerable to risk factors $(\mathrm{n}=32)$; Group 3 (Threatened group) included women hospitalized for threatened miscarriage $(\mathrm{n}=35)$. In Groups 2 and 3, patients were divided into 3 age groups: 18-24 years (a), 25-34 years (b), and $\geq 35$ years (c). Patients in the Control group were divided into 2 age groups, 18-24 years and 25-34 years, since women aged $\geq 35$ years were referred to Group 2.

The psychoemotional status of the women was assessed using the Spielberger State-Trait Anxiety Inventory (STAI) in Yu.L.Khanin's adaptation, ${ }^{(9)}$ and the Eysenck Personality Questionnaire (EPQ). ${ }^{(10)}$ The Spielberger-Khanin inventory is a fairly reliable and highly valid express method, consisting of two separate scales for assessment of state anxiety (anxiety about an event) or anxiety as a personal trait. A scale is a range of scores used to assess the level of anxiety: $\leq 25$ (low level), 26-45 (moderate level), and 46+ (high level). EPQ provided an insight into the intensity of emotional states, namely anxiety, frustration, aggression, and rigidity. Each emotional state was assigned a level ranging from low to high: 0-7 (low level), 8-14 (moderate level), and 15-20 (high level).

Statistical analysis was performed using the Statistica 10.0 software package (Stat-Soft Inc., USA). The normality of distribution of continuous variables was tested by the Kolmogorov-Smirnov test. For descriptive analysis, results are presented as mean $(\mathrm{M}) \pm$ standard error of the mean (SEM). For data with normal distribution, intergroup comparisons were performed using Student's t-test. Differences of continuous variables departing from the normal distribution, even after transformation, were tested by the Mann-Whitney $U$-test. Multiple comparisons were performed with one-way ANOVA and Tukey's HSD Posthoc Test. Group comparisons with respect to categorical variables are performed using chi-square tests. Pearson's Correlation Coefficient (r) was used to determine the strength of the relationship between the two continuous variables. A probability value of $P<0.05$ was considered statistically significant.

The study was carried out in compliance with Ethical Principles for Medical Research Involving Human Subjects, Adopted by the 18th WMA General Assembly, Helsinki, Finland, June 1964, and amended by the 52nd WMA General Assembly, Edinburgh, Scotland, October 2000. All patients gave their written informed consent.

\section{Results and Discussion}

Based on results of scaling self-reported emotional states, mean anxiety and frustration levels in all study groups were low. On the aggression scale, low levels were observed in Groups 1 and 2, and moderate levels in Group 3. Mean rigidity scores were moderate in all patient groups. These results were consistent with those reported in the literature. ${ }^{(11,12)}$

Age-specific analysis of results showed a presence of some statistically meaningful differences between groups on the aggression scale $(P<0.05)$ (Fig.1). Women aged 1824 in Groups 1 and 3, and those aged $\geq 35$ years in Group 2 scored a moderate aggression level, which suggested adequate emotional response to external aggression-inducing factors. All the other age groups showed low levels of aggression. Moreover, aggression tended to reduce with age in Groups 1 and $2(\mathrm{r}=-0.3$ and $\mathrm{r}=-0.4$, respectively). In Group 2, a strong positive correlation was found between age and aggression levels $(\mathrm{r}=0.8)$, and was interpreted as evidence of increasing aggression level as people grow older.

On the rigidity scale, meaningful correlations were observed in Groups 2 and 3. An increase of rigidity levels with age was found in pregnant women in Group $2(\mathrm{r}=0.4)$. In Group 3 , rigidity levels were significantly higher in women aged $\geq 35$ years, suggesting a decline in flexibility of the nervous system, which is usually characterized by constancy of beliefs, moral standards, and personal objectives, etc.

Within Group 3, significant differences were observed on all 4 scales corresponding to emotional states. Women above 35 years scored more than twice as high on anxiety and frustration scales, compared to other age subgroups (Fig.1), which can be attributed to fear of a negative pregnancy outcome, being afraid to fail, or wishing to hide from problems. Frustration goes along with increased anxiety, which was confirmed statistically by a high correlation between frustration and anxiety scales $(\mathrm{r}=0.9)$.

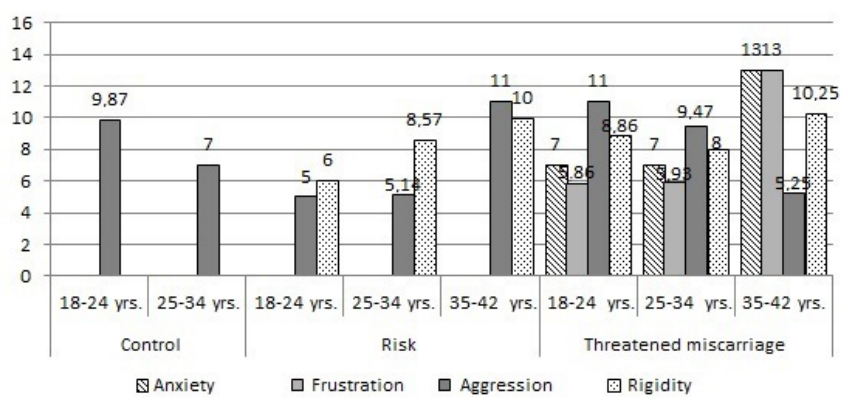

Fig.1. Age-specific EPQ scores of pregnant women, $M$.

Anxiety is a core characteristic of the emotional status of a pregnant woman. ${ }^{(11,12)}$ Therefore, the emotional state of anxiety was analyzed by Spielberger STAI. The results of that inventory showed higher numbers of pregnant women who scored high anxiety levels in northern settings, compared to data from other regions. ${ }^{(13,14)} \mathrm{A}$ certain level of anxiety is a natural and indispensable part of human activity, as it propels adequate summoning up of one's strength and adaptive resources for the purposes of transitioning oneself to a more advanced and optimal level of functioning under existing conditions. A high level of state anxiety (SA) and trait anxiety (TA) characterizes psychoemotional stress, which can cause a mismatch and disorganization of adaptive mechanisms as well as various pregnancy complications leading to miscarriage.

High SA levels signal psychoemotional stress, which can lead to disequilibrium and disorganization of adaptive mechanisms and can be an underlying reason for various pregnancy complications resulting in miscarriage.

In Groups 1 and 2, more than $50 \%$ of women in all 
age subgroups scored high levels of TA (Fig.2). The highest percentages of women with high TA levels were observed among patients aged $\geq 35$ years in Group 3 and among women from Group 1 aged 25-34. High TA levels among those aged 25-34 in Group 1 can be explained by social factors, since women of this age group lead the most active social life.
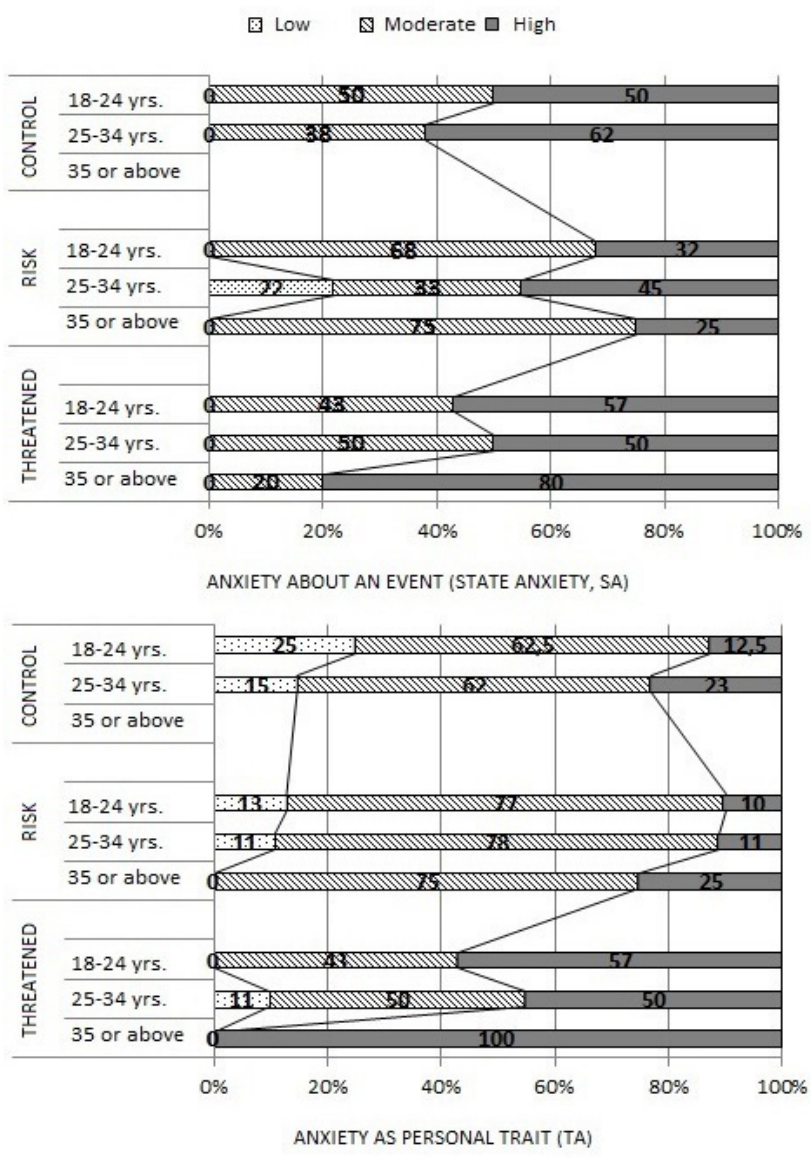

Fig.2. Age-specific percentages of individuals with different levels of state-trait anxiety, $\%$.

High TA levels among women in Group 3 were reasonable, and were probably additionally influenced by the presence of abnormalities detected during pregnancy, general deterioration of women's physical health, etc. The smallest numbers of "high-anxiety" women were observed in Group 2. Moreover, 22\% of women in age subgroup 25-34 in Group 2 had low TA levels, while no women with low TA levels were found in the rest of the groups. Analysis of percentages of patients with high levels of SA showed that Group $3 \mathrm{had}$ the largest number of women who scored high SA levels, including all age subgroups: more than $50 \%$ of women aged $18-24$ years, and $100 \%$ of women aged $\geq 35$ years (Fig. 2 ). The percentages of individuals with high levels of SA tended to increase with age in all groups.

Mean observed SA levels were within the limits of moderate-level anxiety. At the same time, SA levels in Group 3 were significantly higher than in Groups 2 and 1(44.93 \pm 1.77 , $38.29 \pm 1.78$ and $39.93 \pm 1.24$ points, respectfully) $(P=0.0133)$.
Mean TA levels were high in Groups 1 and 3(46.29 \pm 1.25 and $46.8 \pm 1.54$ points, respectfully), and moderate in Group 2 (42.29 \pm 1.11 points) $(P=0.0352)$. Mean SA levels were considered to reflect normal emotional reactivity. High TA levels could probably be caused by contemplating chances of a good pregnancy outcome and the upcoming prospects of motherhood.

Analysis of age-specific mean levels of TA and SA in patient groups showed that both TA and SA levels tended to grow higher with age (Table 1). In Groups 1 and 2, mean SA levels remained within moderate limits in all age subgroups. In Group 3, women in age subgroup of 18-24 scored high anxiety levels $(P=0.0085)$. In all these cases, anxiety played a role as a coping mechanism for a sharp escalation of psychoemotional stress, when pregnancy itself is viewed by women as a stressful situation.

Table 1. Age-specific mean levels of SA and TA in patient groups

\begin{tabular}{|c|c|c|c|c|}
\hline \multirow{2}{*}{ Group } & $\begin{array}{l}\text { 18-24 years } \\
\text { (a) }\end{array}$ & $\begin{array}{l}\text { 25-34 years } \\
\text { (b) }\end{array}$ & $\begin{array}{c}35-42 \text { years } \\
\text { (c) }\end{array}$ & Statistics \\
\hline & \multicolumn{4}{|c|}{ SA } \\
\hline Group 1 & $\begin{array}{l}36.62 \pm 2.85 \\
(n=20)(1 a)\end{array}$ & $\begin{array}{l}39.31 \pm 2.33 \\
(\mathrm{n}=20)(1 \mathrm{~b})\end{array}$ & & $\mathrm{P}=0.4694$ \\
\hline Group 2 & $\begin{array}{c}36.0 \pm 1.85 \\
(\mathrm{n}=20)(2 \mathrm{a})\end{array}$ & $\begin{array}{l}39.22 \pm 3.21 \\
(\mathrm{n}=20)(2 \mathrm{~b})\end{array}$ & $\begin{array}{c}42.5 \pm 3.18 \\
(n=18)(2 \mathrm{c})\end{array}$ & $\mathrm{P}=0.2741$ \\
\hline Group 3 & $\begin{array}{l}46.14 \pm 2.03 \\
(n=15)(3 a)\end{array}$ & $\begin{array}{l}43.61 \pm 1.70 \\
(n=20)(3 b)\end{array}$ & $\begin{array}{c}48 \pm 0.89 \\
(n=14)(3 c)\end{array}$ & $\mathrm{P}=0.1782$ \\
\hline Statistics & $\begin{array}{c}\mathrm{P}=0.0085 \\
\mathrm{P}_{1 \mathrm{a}-3 \mathrm{a}}=0.0207 \\
\mathrm{P}_{2 \mathrm{a}-3 \mathrm{a}}=0.0128\end{array}$ & $\mathrm{P}=0.3692$ & $\mathrm{P}=0.1478$ & \\
\hline Group & \multicolumn{4}{|c|}{ TA } \\
\hline Group 1 & $\begin{array}{l}44.23 \pm 1.21 \\
(\mathrm{n}=20)(1 \mathrm{a})\end{array}$ & $\begin{array}{l}47.71 \pm 1.10 \\
(\mathrm{n}=20)(1 \mathrm{~b})\end{array}$ & & \\
\hline Group 2 & $\begin{array}{c}40 \pm 2.23 \\
(\mathrm{n}=20)(2 \mathrm{a})\end{array}$ & $\begin{array}{l}42.89 \pm 3.25 \\
(\mathrm{n}=20)(2 \mathrm{~b})\end{array}$ & $\begin{array}{l}43.25 \pm 1.89 \\
(\mathrm{n}=18)(2 \mathrm{c})\end{array}$ & $\mathrm{P}=0.6169$ \\
\hline Group 3 & $\begin{array}{l}45.56 \pm 1.21 \\
(\mathrm{n}=15)(3 \mathrm{a})\end{array}$ & $\begin{array}{l}44.89 \pm 1.86 \\
(\mathrm{n}=20)(3 \mathrm{~b})\end{array}$ & $\begin{array}{c}55.4 \pm 3.07 \\
(\mathrm{n}=14)(3 \mathrm{c})\end{array}$ & $\begin{array}{c}\mathrm{P}=0.019 \\
\mathrm{P}_{3 \mathrm{a}-3 \mathrm{c}}=0.0089 \\
\mathrm{P}_{3 \mathrm{~b}-3 \mathrm{c}}=0.0026\end{array}$ \\
\hline Statistics & $\mathrm{P}=0.0633$ & $\mathrm{P}=0.3223$ & $\begin{array}{c}\mathrm{P}=0.0014 \\
\mathrm{P}_{2 \mathrm{c}-3 \mathrm{c}}=0.0014\end{array}$ & \\
\hline
\end{tabular}

Analysis of mean TA levels showed the presence of reliably high levels of TA among the 25-34 subgroup in Group 1 , while in the other age groups, TA levels remained within a moderate range. In Group 2, TA levels did not differ much between different ages, and remained within moderate limits. Pregnant women in Group 3 scored reliably high TA levels in age subgroups $18-24$ and $\geq 35$. Moreover, women aged $\geq 35$ years showed very high mean levels of TA $(P=0.0014)$.

$\mathrm{TA}$ is defined as one of the most stable individual characteristics reflecting person's predisposition to anxiety.(7) High TA levels in pregnant women with threatened miscarriage can probably be one of the reasons for a predicted unfavorable pregnancy outcome, since any alteration in a woman's physical state can be perceived as negative or dangerous. Anxiety as a personality trait can largely underlie human behavior. 
In conclusion, the results of our study showed the presence of age-specific features in the psychophysiological state of pregnant women living in the North, specifically, high anxiety levels. In all patient groups, psychoemotional stress tended to increase with age. The highest stress levels were observed among pregnant women from the Threatened miscarriage group, especially in 2 age subgroups (18-24 years and $\geq 35$ years).

\section{Competing Interests} interests.

The authors declare that they have no competing

\section{Sources of Funding}

The reported study was conducted as part of Project VI.62.1.8. «Development of bio-products derived from tissues of plants and animals of Yakutia based on explorations of their biochemical composition and mechanisms of adaptation to northern environments» (No. 0376-2019-0005, Registration Number AAAA-A17-117020110055-3).

\section{References}

1. Agarkova LA, Buharina IY, Ulianich AL, Vershkova EM, Tolmachev IV. Features of quality of life interrelated with indicators of psychoemotional state of women in the period of every trimestre of pregnancy. Bulletin of Kemerovo State University. 2016;(4):108-119. doi: 10.21603/2078- 89752016-4-108-119. [Article in Russian].

2. Gatsaeva LT, Torchinov AM, Filippova GG, Tsakhilova SG. Course of pregnancy, labor, and postpartum period in women in presence of mixed anxiety and depression disorders under conditions of socio-economic instability. Reproduktivnoe Zdorove Detei I Podrostkov. 2011;(3):66-73 [Article in Russian].

3. Khlomov KD, Enikolopov SN. Study of psychoemotional and individual character features of pregnant women with threatened miscarriage. Perinatalnaya Psikhologiya i Psikhologiya Roditelstva. 2007;(3):38-49. [Article in Russian]. 4. Thorsness KR, Watson C, LaRusso EM. Perinatal anxiety: approach to diagnosis and management in the obstetric setting. Am J Obstet Gynecol. 2018;219(4):326-345. doi: https://doi. org/10.1016/j.ajog.2018.05.017

5. Kim DR., Connolly KR., Cristancho P, Zappone M, Weinrieb RM. Psychiatric consultation of patients with hyperemesis gravidarum. Arch Womens Ment Health. 2009;12(2):61-67. doi: 10.1007/s00737-009-0064-7.

6. Strizhova NV, Sabakh Abu El. Kheidzha. Predictive significance of yolk sac sonography in pregnancy miscarriage. Vestnik Rossiiskoi Assotsiatsii Akusher-Ginekologov. 1995;2:56-58. [Article in Russian].

7. Kolosova ON, Yakovleva AP, Shits IV. Characteristics of health status in women of reproductive age in Yakutia. Byulleten' Natsionalnogo Nauchno-Issledovatelskogo Instituta Obshchestvennogo Zdorovya im. N.A. Semashko.2012;(4):69-70. [Article in Russian].

8. Nikolaeva EN. Psychophysiological patterns in adaptation of college students to northern environment. Abstract of $\mathrm{PhD}$ Thesis. Yakutsk; 2006. [In Russian].

9. Khanin YL. A brief guide to the use of a scale of reactive and personal anxiety by Ch.D. Spielberger. Leningrad.: LNII FC; 1976. [In Russian].

10. Eysenck HJ \& Eysenck SBG. The Eysenck Personality Questionnaire.London: Hodder \& Stoughton. 1975.

11. Belyaeva OA. Features of the emotional sphere of pregnant women. Collection of scientific works «Estestvoznanie i gumanizm».2002;2(5):43-51. [Article in Russian].

12. Andrienko O.A. Study of anxiety in pregnant women of different age groups. International scientific journal «Symbol of Science».2016;(5):224-225. [Article in Russian].

13. Gopurova G.F. [Psychoemotional changes in women during pregnancy period]. Proceedings of the 2 nd International scientific conference. Ufa;2014:21-25. [In Russian].

14. Abdullaeva VK. Features of psycho-emotional changes in women during pregnancy. ISJ Theoretical \& Applied Science. 2017;02(46):122-124. doi:10.15863/TAS.2017.02.46.22. 